\title{
Knee Maturation as a Differentiating Sign between Congenital Rubella and Cytomegalovirus Infections
}

\author{
L. R. Kuhns ${ }^{1}$, T. Slovis ${ }^{2}$, R. Hernandez ${ }^{1}$, and A. K. Poznanski ${ }^{1}$ \\ ${ }^{1}$ C. S. Mott Children's Hospital, University of Michigan Medical Center, Ann Arbor, Michigan, and ${ }^{2}$ Michigan \\ Children's Hospital, Detroit, Michigan, USA
}

\begin{abstract}
Knee epiphyseal maturation is retarded in most neonates with congenital rubella infection, whereas neonates with congenital cytomegalovirus infection have relatively normal maturation. Assessment of knee maturation is useful in differentiating rubella from cytomegalovirus infection in the neonate.
\end{abstract}

Key words: Knee maturation - Congenital rubella infection - Congenital cytomegalovirus infection Intracranial calcifications

Knee radiographs are often obtained when an intrauterine infection is suspected in the neonate. Linear metaphyseal striations were originally thought to be specific for congenital rubella infection, but recently these striations have also been observed in congenital cytomegalovirus infection $[1,5,6,11]$. On knee radiographs which were obtained to visualize these striations, we have noted that epiphyseal maturation tends to be more retarted in the neonate with rubella than with cytomegalovirus infection. This study was undertaken to determine the extent of knee ossification in neonates with these two congenital infections.

\section{Material and Methods}

All neonates who were full term by history, who had knee radiographs within the first ten days of life, and who had congenital viral infections proven by virus culture, antibody titre determinations, or autopsy results at C.S. Mott Children's Hospital or Michigan Children's Hospital were included in this study. Neonates reported in the literature who fulfilled these criteria were also included in the study $[1,2,4-8,10-12]$. Presence or absence of ossification of the distal femoral epiphysis and the proximal tibial epiphysis was recorded. Presence or absence of metaphyseal striations or intracranial calcifications was also recorded.

\section{Results}

Ten neonates with congenital rubella infection were assessed. Seven had no ossification of either knee epiphysis (Figs. 1 and 3). Ten neonates with congenital cytomegalovirus infection were assessed. Seven of these had both distal femoral and proximal tibial epiphyses ossified (Fig. 2), indicating a statistically significant difference between knee ossification of the two groups $\left(\mathrm{X}^{2}=\right.$ $4.8, \mathrm{p}<.05$ ). Metaphyseal "celery-stalking" was seen in six neonates with cytomegalovirus infection and in all ten with rubella, but this series includes cases previously published because of the presence of metaphyseal striations; therefore the incidence of metaphyseal striations in these infections cannot be ascertained from this study. Of the six neonates with cytomegalovirus infection and metaphyseal striations, four had both knee epiphyses ossified and two had visible distal fe- 


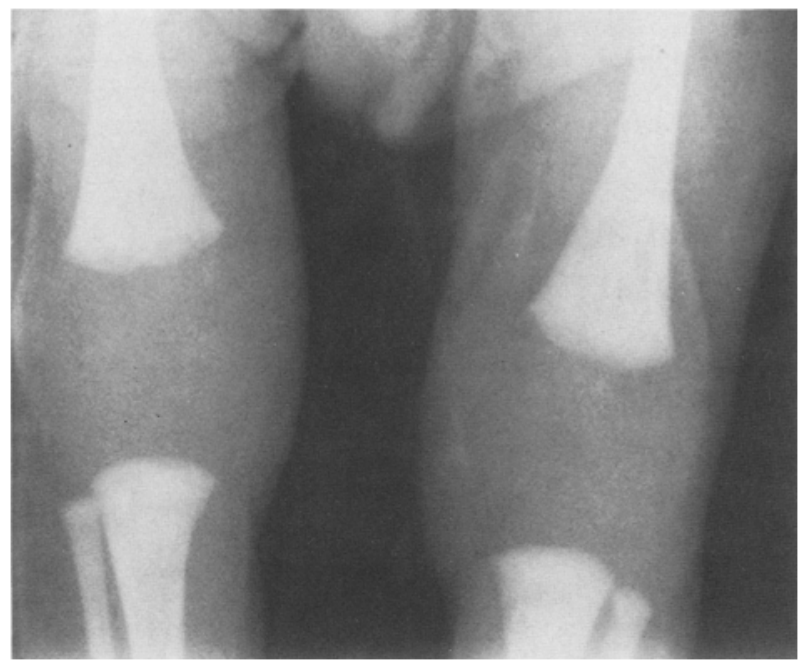

Fig. 1. This small for gestational age, term neonate had jaundice, hepatosplenomegaly, thrombocytopenia with "blueberry muffin" skin lesions, and microcephaly. Fine linear metaphyseal striations are present in the metaphyses, and knee epiphyseal maturation is retarded. Diagnosis was congenital rubella infection with positive cultures

moral ossification, so that there was no correlation between metaphyseal striations and lack of epiphyseal ossification in these neonates. Four of the neonates with cytomegalovirus infection had intracranial calcifications, whereas none of those with rubella infection had intracranial calcifications $\left(\mathrm{X}^{2}=7.8, \mathrm{p}<.01\right)$.

\section{Discussion}

When a newborn infant has clinical signs srongly suggesting an intrauterine viral infection, as did all neonates in this study, either the rubella or cytomegalovirus virus is usually the infecting agent. Metaphyseal striations are seen in both types of infection, but the rubella virus retards epiphyseal ossification much more than the cytomegalovirus, and this is a useful roentgen feature in distinguishing one from the other. By noting the extent of knee epiphyseal maturation we have correctly predicted the infecting virus in our last two neonates with congenital viral infections (Figs. 1 and 2) several weeks before the results of viral cultures and antibody titres were available.

Another useful sign in differentiating between rubella and cytomegalovirus infections is intracranial calcification. Four of ten neonates with cytomegalovirus infection had intracranial calcifications in this study (Fig. 2), whereas none of the rubella neonates in this study or in the series of Korones [3] had intracranial calcifications. We know of only one reported neonate with definitely proven rubella infection who had intracranial calcifications [9]. Therefore, when intracranial calcifications are seen in association with well ossified knee epiphyses, cytomegalovirus infection should be strongly suspected rather than rubella infection. In this series, the one neonate with no visible knee epiphyses and a cytomegalovirus infection did
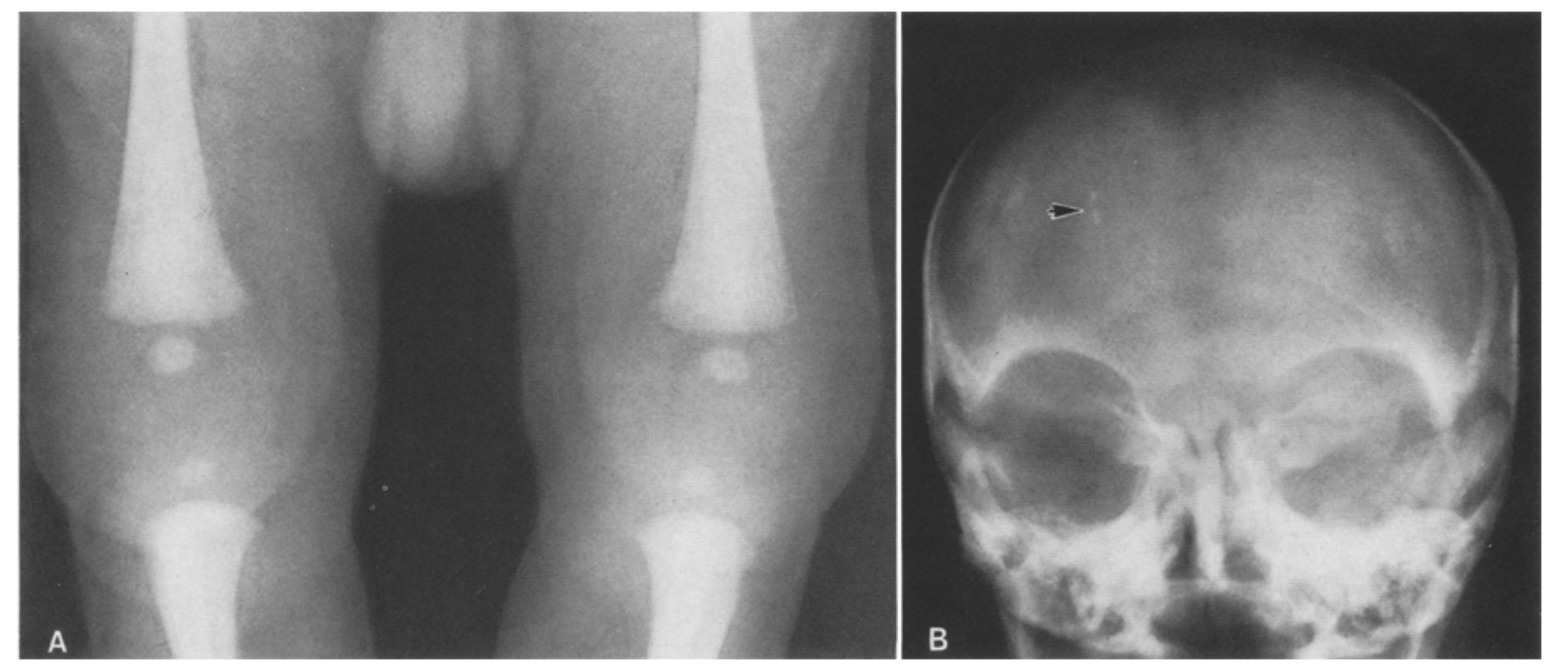

Fig. 2. A This term neonate had the same clinical signs as the patient in Figure 1, so that a congenital viral infection was strongly suspected. Knee epiphyseal maturation is normal for a term gestation and no metaphyseal striations are seen. B Intracranial calcifications are noted (arrowhead) in this infant. Radiological diagnosis was congenital cytomegalovirus infection because of the normal maturation and intracranial calcifications, and this was confirmed by viral cultures 


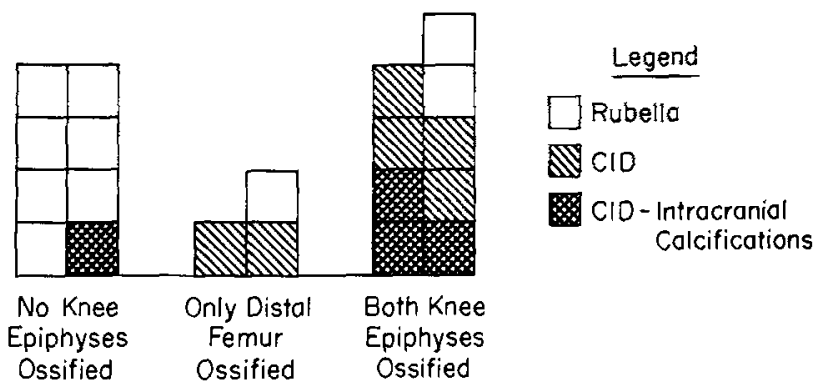

Fig. 3. Knee epiphyseal maturation was markedly retarded in seven of ten term neonates with rubella. Nine of ten term neonates with congenital cytomegalovirus infection had at least one epiphyseal center ossified. Well ossified distal femoral and proximal tibial epiphyses were present more often than intracranial calcifications in neonates with congenital cytomegalovirus viremia

have intracranial calcifications (Fig. 3); with these roentgen findings, cytomegalovirus infection should be suspected even though knee maturation is retarded.

Acknowledgement. We thank C. Benjamin Graham, M. D. for the radiographic results of one unpublished neonate with cytomegalovirus infection.

\section{References}

1. Graham, C. B., Thal, A., Wassum, C. S.: Rubella-like bone changes in congenital cytomegalic inclusion disease. Radiology 94, 39 (1970)

2. Highman, J. H.: Congenital osseous rubella. Clin Radiol. 18, 445 (1967)

3. Korones, S. B., Ainger, L. E., Monif, G. R. G., Roane, J., Sever, J. L., Fuste, F.: Congenital rubella syndrome: New clinical aspects with recovery of virus from affected infants. J. Pediatr. 67, 166 (1965)
4. Marquis, J. R., Lee, J. K.: Extensive central nervous system calcification in a stillborn male infant due to cytomegalovirus infection. Am. J. Roentgenol. Radium Ther. Nucl. Med. 127, 665 (1976)

5. McCandless, A. E., Davis, C., Hall, E. G.: Bone changes in congenital cytomegalic inclusion disease. Arch. Dis. Child. 50, 160 (1975)

6. Merten, D. F., Gooding, C. A.: Skeletal manifestations of congenital cytomegalic inclusion disease. Radiology 95, $333(1970)$

7. Rabinowitz, J. G., Wolf, B. S., Greenberg, E. I., Rausen, A. R.: Osseous changes in rubella embryopathy (Congenital rubella syndrome). Radiology 85, 494 (1965)

8. Rausen, A. R., London, R. D., Mizrahi, A., Cooper, L. Z.: Generalized bone changes and thrombocytopenic purpura in association with intrauterine rubella. Pediatrics 36, 264 (1965)

9. Rowen, M., Singer, M. I., Moran, E. T.: Intracranial calcification in the congenital rubella syndrome. Am. J. Roentgenol. Radium Ther. Nucl. Med. 115, 86 (1972)

10. Rudolph, A. J., Yow, M. D., Phillips, C. A., Desmond, M. M., Blattner, R. J., Melnick, J. L.: Transplacental rubella infection in newly born infants. J. A. M. A. 191, 139 (1965)

11. Sacrez, R., Fruhling, L., Korn, R., Juif, J.-G., Francfort, C., Geiger, R.: Trois observations de maladie des inclusions cytomegaliques. Arch. Fr. Pediatr. 17, 129 (1960)

12. Whalen, J. P., Winchester, P., Krook, L., O'Donohue, N., Dische, R., Nunez, E.: Neonatal transplacental rubella syndrome. Its effect on normal maturation of the diaphysis. Am. J. Roentgenol. Radium Ther. Nucl. Med. 121, $166(1974)$

Date of final acceptance: April 2, 1977

L. R. Kuhns, M. D.

Division of Pediatric Radiology

C. S. Mott Children's Hospital

University of Michigan Medical Center

Ann Arbor, MI 48109

USA 